\title{
Health in Optimal Fitness and its Related Factors in Young Korean Children Born Prematurely
}

\author{
Sangmi Lee', Min Sohn², Shinjeong Kim³ ${ }^{3}$ Sunha Choi ${ }^{4}$, Yonghoon Jun², Youngmee Ahn² \\ ${ }^{1}$ Dongyang University, Yeongju; ${ }^{2}$ Inha University, Incheon; ${ }^{3}$ Hallym University, Chuncheon; ${ }^{4}$ Gangneung-Wonju National University, Gangneung, Korea
}

Purpose: This study was conducted to describe health in optimal fitness (HOF) in young children born prematurely and to analyze factors affecting HOF in health status, investment resources, and anthropological values, based on HOF theory. Methods: A case-control study of 76 children with preterm births (PTB) was conducted at 24 to 42 months of corrected age. Their HOF status was evaluated based on height, weight, head circumference, and the Korean-Bayley Scale of Infant Development-II and classified as either HOF-achieved or HOF-uncertain in the domain of growth, development, and all together. Results: For growth, development, and all, 26.3\%, 27.6\%, and 47.4\% of children, respectively, belonged to the HOF-uncertain group. Logistic regression analysis showed that longer length of hospital stay ( $\geq 21$ days; OR $=7.8 ; 95 \%$ CI $[1.5,40.5])$, worse scores on the Home Observation for Measurement of the Environment (HOME) ( $\geq 38$; OR $=0.1 ; 95 \%$ CI $[0.0,0.4])$, having a working mother, $(\mathrm{OR}=5.7 ; 95 \% \mathrm{CI}[1.2,27.6])$, and an older mother ( $\geq 35$ years; $\mathrm{OR}=8.8 ; 95 \% \mathrm{CI}[2.1,37.3]$ ) were statistically significant contributors of HOF-uncertain in the domain of all. Conclusion: Findings show that young children born prematurely with prolonged stays in a neonatal intensive care unit and insufficient socioeconomic resources at home are more likely to exhibit delayed growth and development.

Key words: Preterm birth, Child, Growth and development, Health status, Investments.

\section{Introduction}

Despite Korea's extremely low fertility rate, the rate of preterm birth (PTB) has steadily increased from 3.8\% in 2000 to 6.7\% in 2014[1]. During this time, improvements in prenatal care and the development of nursing and medical technologies for high-risk infants have accounted for a rapid increase in the survival rate of children born prematurely. For this population, growth and development is an important indicator of health outcomes, and this indicator has been widely compared in fullterm infants over a wide range of ages[2]. Children with PTB are known

\footnotetext{
Corresponding author Sangmi Lee Dongyang University, 145, Dongyangdae-ro, Punggi-eup, Yeongju 36040, Korea

TEL +82-54-630-1712 FAX+82-54-630-1371 E-MAIL Ism95adyu.ac.kr

*This manuscript is based on the first author's doctoral dissertation from Inha University

*This research was supported by Basic Science Research Program through the National Research Foundation of Korea (NRF) funded by the Ministry of Science, ICT \& Future Planning (grant number : NRF-2014R1A1A1002091).

Key words Preterm birth, Child, Growth and development, Health status, Investments Received 1 September 2016 Received in revised form 11 October 2016 Accepted 12 October 2016
}

(c) This is an Open Access article distributed under the terms of the Creative Commons Attribution NonCommercial License (http://creativecommons.org/licenses/by-nc/4.0/) which permits unrestricted noncommercial use, distribution, and reproduction in any medium, provided the original work is properly cited. to have delayed growth and development, which can be seen in childhood and adolescence[3]. Traditionally, growth and development in children with PTB have been studied from a biological point of view. Few studies have examined this population in terms of interaction with environment and culture, although the body of knowledge on childbearing and caring has a long history in human studies, for example, anthropology[4,5].

Although Spencer was the first to introduce the term fitness, Hamilton developed the concept to apply to human adaptation and reproduction in the evolutionary sense[6]. Optimal fitness means to maximize one's ability to survive and grow in balance between quality of a human being and quantity of human beings with genetic commons[7]. It is achieved through the successful interaction of a population and an environment. Environment, which influences optimal fitness in human beings, is called environment of evolutionary adaptedness (EEA). EEA for human beings includes cultural, social, and economic characteristics. According to Bowlby[8], EEA is more influential for children than adults. He explains that children need additional resources to reach optimal fitness because of dependent and passive characteristics in their developmental stage, and the type and degree of resources available to them are often determined by familial and social values. 


\section{Health in optimal fitness}

Health is one of the most important domains of optimal fitness. Although managing the health of children is uniquely different from doing so for adults, most theories have been advanced for adults. Optimal fitness is an even more important concept for high-risk infants, such as those born prematurely, because growth and development and survival are so critical. Yet, few theories on this subject have been developed despite the increasing prevalence of PTB over several decades. Ahn[7], a nursing scientist who specializes in high-risk infant care and a biomedical anthropologist, developed an integrated theory to explain optimal fitness and related factors for high-risk Korean infants. She advanced the concept of optimal fitness in the care and management of high-risk children and developed a theoretical framework called health in optimal fitness (HOF) (Figure 1).

HOF in high-risk infants means not being free of health problems but being fit throughout the process of survival, growth, and development[7]. The instrumental definition of HOF can be challenging for researchers and clinicians alike. Growth and development indicators (i.e., weight, height, head circumference, and development assessment) are commonly used to forecast health for children with PTB. Also, they are fundamental to the concept of HOF. Although height, weight, head circumference, and development status are integral attributes of human growth and development, many researchers have treated the indicators separately for practical reasons.

According to Ahn's theory[7], the health status of high-risk children, like those born prematurely, is the most important factor for their optimal fitness. Children with PTB are at high-risk for several health problems and growth and developmental issues that can diminish optimal fitness. Of course, they may require more investment resources for health management, and if resources are limited, the types and degrees of investments are often determined by their relative anthropological values[7]. Hence, high-risk infants can achieve HOF not only as it pertains to their health status but also to investment resources and anthro-

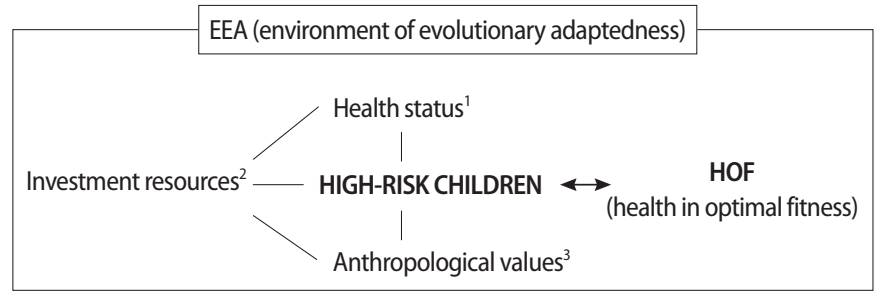

Figure 1. Theoretical model of health in optimal fitness theory (Ahn, 2009). Numbers $1,2,3=$ factors of HOF in high-risk children. pological values in a given EEA. For example, in today's EEA, the survival rate of high-risk infants has improved over past years because of advances in medical and social resources. In Korean society especially, anthropological values and concern for HOF in high-risk children is rising caused by an extremely low fertility rate of $1.2[9]$ and rapid modernization.

Health status refers to (a) the health of children assessed at birth (gestational age, birth weight, Apgar score, delivery type, twins, health problems) or while in a neonatal intensive care unit (NICU), (b) the current health problems of children, and (c) the perinatal health of mothers (maternal age, health problems).

Investment resources refer to family or social resources that can be invested in children. These resources may include the parents' socioeconomic status, the adequacy of the home environment for parenting, breastfeeding, the availability of a helper, or child care resources in the community such as government-sponsored health centers. Breasts in Korean women are perceived to be a symbol of female sexuality; changes in breast shape as the result of breastfeeding are recognized to be a threat to that symbol[10]. Thus, for Korean women, breastfeeding as an investment in the natural nourishment of their child puts them at risk of jeopardizing their own perceived sexuality. Currently, most young, Korean couples have only one child[9], which limits their child care experience. This unfamiliarity may cause parents of high-risk children, such as those born prematurely, to seek experienced and dependable child care from others, usually grandparents. Although Korea enacted national health insurance in the early 1980s, coverage, in scope and proportion, is oriented to common health problems rather than specific conditions such as premature birth. In addition, most Korean women have low-quality jobs with the greatest wage differential by gender of any nation[11], which creates more economic burden in rearing a child with PTB.

Anthropological values refer to the relative value of children in their family and society. In contrast to investment resources, which are external by definition, anthropological values reflect the internal value of children in their social environment. These values are determined by children's gender, birth order, mother's age, siblings, and the relationship between parents and children such as maternal attachment and parenting stress. For example, Korean families have a traditional culture of paternalism and strong fondness for boys, which dates backs 5,000 years. The first male child is unquestionably considered the heir in traditional, Korean, male-oriented families and the family's representative in social activities. Hence, the economic and social values of boys are higher than 
those of girls. However, in this regard, rapid modernization and industrialization caused by globalization is changing Korean culture. According to Ahn[7], alternatives to children with PTB, such as healthy siblings (birth order) and the fertility function of parents (maternal age), are important determinants of anthropological values. Families with young mothers or healthy siblings can go on even if a child with PTB does not survive. The relative value of such children can be challenging for those families. Maternal-child attachment is defined as the intimate emotional bond between mother and child[8]. This bond fosters a unique relationship between the two that enhances a child's relative value within the family. A mother's strong attachment to a specific child may increase that child's relative value within the family. By contrast, severe parenting stress may cause a negative maternal-child relationship to fester, one that emotionally devalues the child.

\section{Study purposes}

For this study, we targeted children with PTB between 24 to 42 months of corrected age due to the phenomenon of slow growth rate after the initial period of rapid growth[3] and the applicable age range (up to 42 month) of the Korean-Bayley Scale of Infant Development-II (KBSID-II) to assess children's development[12]. Their growth and development is strongly related to growth and development in later life. The purpose of this study, therefore, was to describe HOF in this sample of children and to evaluate factors of HOF in the domains of health status, investment resources, and anthropological values, based on HOF theory.

\section{Methods}

\section{Study design}

This was a case-control study of children with PTB between the ages of 24 and 42 months of corrected age.

\section{Setting and sample}

Potential participants were identified based on a review of medical records of such children who were born in a university hospital in Korea between July 2008 and February 2010. In this study, we surveyed all children who fit the inclusion criteria and the exclusion criteria. Children with PTB who were born at 28 to 37 weeks and appropriate for gestational age (AGA) based on birth weight were included in the study. Children with PTB were excluded if they had been born earlier than 28 weeks of gestational age, had chromosomal or congenital disorders, and were already receiving developmental intervention such as rehabilitation therapy. In addition, children were excluded if they had been adopted, moved to other regions, or died.

Of the 231 children who were eligible, 96 infants (41.6\%) were excluded because their parents were unable to be contacted by telephone or other means of communication. In addition, of the 135 remaining children, 59 (43.7\%) were ineligible to participate in the study because their parents declined. Ultimately, 76 eligible children were enrolled in this study.

\section{Measurements}

We assessed HOF for children in the domain of growth (weight, height, head circumference), development (mental, psychomotor), and all together. HOF for growth was determined by comparing a child's weight, height, and head circumference with the Korean standard growth curve for children and adolescents[13]. Their HOF in development was assessed by the Mental Development Index and Psychomotor Development Index of the K-BSID-II. If children met all required targets in the growth and development domains, they were classified as HOFachieved in growth or development. If they met all targets in the growth and development domains together, they were classified as HOFachieved in all. If they had not met at least one of the targets in the growth and development domains, they were classified as HOF-uncertain in growth or development. If they had not met at least one of the targets in growth and development domains together, they were classified as HOF-uncertain in all.

We also assessed factors associated with health status, investment resources, and anthropological values. Health status factors included gestational age, birth weight, Apgar score at 5 minutes, length of hospital stays in an NICU, being a twin, Cesarean delivery, health problems of the child at birth, current health problems, maternal age at birth, and perinatal health problems of mothers. Factors related to investment resources included maternal education, mothers with employment, paternal education, fathers having a regular job, duration of breastfeeding, number of members in family, home observation for measurement of the environment (HOME), grandparental help for the child, and the availability of material support for child care from the government. Factors associated with anthropological values included female gender of the child, birth order, having brothers, having sisters, current maternal age, parenting stress, and maternal attachment. Most of the above information was collected by structured questionnaire during home visits 
with the children's mothers. Other information was obtained from the children's hospital records, which included birth history, NICU history, and mothers' delivery history.

\section{Weight, height, and head circumference}

In this study, we defined children's growth to be HOF-achieved if their weight, height, and head circumference were in the 10-90th percentile of Korean growth standards. We used this range because it is an AGA standard and recommended in the literature to detect and manage growth retardation early on in children at risk of delayed growth[14]. If any measurement fell outside of that range, children were classified as HOF-uncertain in growth.

With children wearing only thin clothes and a diaper, weight was measured in kilogram units up to the first decimal point using a weight scale made by CAS Corporation, Korea. Height and head circumference were measured in centimeters to the first decimal point using a flexible tape measure. Recumbent length was measured; head circumference was measured by taking the greatest occipitofrontal circumference from the supraorbital ridge to the occiput. To minimize measurement error, height, weight, and head circumference measurements were taken twice. If measurements were inconsistent, a third measurement was taken to establish consistency with one of the other measurements.

\section{Korean-Bayley Scale of Infant Development-II}

A specially trained researcher conducted the K-BSID-II. This developmental test is the standardized Korean version of the BSID-II[15], which measures children's cognitive abilities and motor development up to 42 months[12]. The test is comprised of the Mental Development Index that measures a child's cognitive, linguistic, and personal-social abilities and the Psychomotor Development Index that measures motor control of gross and fine muscles. Each test is standardized to a mean (SD) score of 100 (15), which is considered to be normal development if the score is $\geq$ mean 1SD and impaired development if the score $<$ mean-1SD. Thus, if each test score exceeded 85 points, children were classified as HOFachieved in development; if a score was under 85 for either of the two developmental indices, children were classified as HOF-uncertain in development.

\section{Home Observation for Measurement of the Environment}

A Korean version of HOME, which was originally developed by Caldwell and Bradley[16] and translated by Lee[17], was used to assess the quality of the home environment for child development. HOME consists of 45 questions in six subscales: parental responsivity, acceptance of child, organization of the environment, learning materials, parental involvement, and variety in experience. Each question was scored either yes or no based on our observations and interviews with the mothers of our participant children. Higher scores represent a more enriched environment for child development. The validity of HOME was examined by Caldwell and Bradley[16]. Kuder-Richardson-20 was .90 in Lee's research[17] and .70 in this study.

\section{Maternal Attachment Inventory}

The Maternal Attachment Inventory, which was developed by Muller[18] and adapted to Korean by Han[19], was used to measure the degree of attachment between the mother and the infant. This inventory comprises 26 questions, and responses are recorded on a 4-point scale. Higher scores represented higher levels of maternal attachment. The validity of this inventory was examined in Muller's research[19]. Cronbach's alpha was .89 in Han's research[19] and .92 in this study.

\section{Parenting Stress Index}

Developed by Abidin[20] and translated into Korean by Lee et al.[21], the Parenting Stress Index uses 36 questions to measure the stress experienced by parents while raising a child. Answers were recorded on a 5-point scale; higher scores represent higher levels of parental stress. The validity of this index was examined in the research by Lee et al.[21]. Cronbach's alpha was .91 in the research by Lee et al.[21] and .89 in this study.

\section{Data collection}

We collected data from the children's electronic medical records and home visits between January and April 2012, after the hospital's Institutional Review Board approved the study (IRB no. IUH-IRB 2012-0096). All data were collected by a researcher who had the K-BSID-II certificate. We telephoned mothers to explain the study, its purpose, and procedures and to arrange for a home visit. Each family was scheduled for just one home visit. At these visits, mothers provided written consent for study participation. Physical measurements and K-BSID-II examination of the children were performed at the visits, and mothers were asked to complete the structured questionnaires. After the questionnaires had been completed, interviews were conducted with mothers for HOME. 


\section{Data analysis}

Data were analyzed with SPSS Statistics 20.0 for the Windows program. The normality of main variables in this study (Mental Development Index, Psychomotor Development Index, HOME, Maternal Attachment Inventory, and Parenting Stress Index) was met because their skewness was in $-1.21 \sim-0.33$ and their kurtosis was in $-0.35 \sim 1.99$. Descriptive statistics were used to describe the children's general characteristics and HOF for growth, development, and all. Independent t-tests and $\chi^{2}$-tests were used to explain the relationship of health status, investment resources, anthropological values, and the HOF of growth, development, and all.

Logistic regression analysis was used to investigate the effect of factors on health status, investment resources, and anthropological values on HOF. We used this form of analysis because the dependent variable was a binomial variable, and odds ratios (ORs) are more likely to help clinicians understand the interpretation of our analysis. Most of the continuous variables were converted to nominal variables with cut-offs, which were the mean value. However, we defined cut-offs except for the duration of breastfeeding[22] and the score of parenting stress index[21] based on references. Two models were developed to predict HOF-uncertain for growth, development, and all. In Model 1, we included variables that are known to be significantly related to child growth and development, as shown in previous studies, and that showed a significant relationship based on correlation analysis. Previously reported variables associated with children's growth and development included gestational age, mothers with employment, duration of breast feeding, HOME, female gender of the child, current maternal age, total score on the parenting stress index, and total score on the maternal attachment inventory $[3,7,22,23]$. In Model 2, we selected independent variables from the variables that showed a significant relationship with HOF-uncertain in Model 1.

\section{Results}

\section{General characteristics and HOF frequencies of subjects}

As noted in Table 1, the average gestational age and weight of children at birth were 33.5 weeks and $2110 \mathrm{~g}$, respectively. Of the 76 participants, $47.4 \%$ of girls and $69.7 \%$ of boys were born by cesarean delivery. The Apgar score at $5 \mathrm{~min}$ averaged 7.8. As for birth order, 53.9\% were a second or later child, and the corrected age of the children averaged 31.6 months $(\mathrm{SD}=4.3)$ at the time of data collection.
Table 1. Participant Characteristics and HOF-Achieved Frequencies

$(\mathrm{N}=76)$

Mean (SD, range) Frequency (\%)

\begin{tabular}{|c|c|c|}
\hline Health status & & \\
\hline Current age of child (month) & $31.6(4.3,24-41)$ & \\
\hline Gestational age (week) & $33.5(2.2,28.3-36.7)$ & \\
\hline Birth weight (gram) & $2110(518,862-3220)$ & \\
\hline Apgar score at 5 minutes & $7.8(1.3,2-10)$ & \\
\hline NICU length of stay (day) & $23.7(18.1,5-75)$ & \\
\hline Maternal age at birth (year) & $31.8(3.9,21-40)$ & \\
\hline Twins & & $20(26.3)$ \\
\hline Cesarean delivery & & $53(69.7)$ \\
\hline Health problems of child at birth & & $24(31.6)$ \\
\hline Current health problems of child & & $30(39.5)$ \\
\hline Perinatal health problems of mothers & & $57(75.0)$ \\
\hline Investment resources & & \\
\hline High school graduated mothers & & $40(52.6)$ \\
\hline Mothers with employment & & $26(35.6)$ \\
\hline High school graduated fathers & & $33(43.4)$ \\
\hline Fathers having a regular job & & $59(77.6)$ \\
\hline Duration of breast feeding (month) & $9.9(6.8,1-36)$ & \\
\hline Number in family & $4.2(1.1,3-9)$ & \\
\hline HOME & $38.8(3.3,28-44)$ & \\
\hline Grandparental help for child not available & & $47(61.8)$ \\
\hline Child care resources in the community & & $7(9.2)$ \\
\hline Anthropological values & & \\
\hline Female child & & $36(47.4)$ \\
\hline Birth order $\geq 2$ nd & & $41(53.9)$ \\
\hline Having brothers & & $34(44.7)$ \\
\hline Having sisters & & $35(46.1)$ \\
\hline Current maternal age (year) & $36.0(4.0,25-44)$ & \\
\hline Parenting Stress Index & $83.1(16.5,42-115)$ & \\
\hline Maternal Attachment Index & $96.6(7.4,77-104)$ & \\
\hline HOF- Achieved all & & $40(52.6)$ \\
\hline Growth-All & & $56(73.7)$ \\
\hline Weight & & $68(89.5)$ \\
\hline Height & & $74(97.4)$ \\
\hline Head circumference & & $62(81.6)$ \\
\hline Development- All & & $55(72.4)$ \\
\hline Mental Development Index & & $62(81.6)$ \\
\hline Psychomotor Development Index & & $55(72.4)$ \\
\hline
\end{tabular}

$\mathrm{HOF}=$ health in optimal fitness; $\mathrm{NICU}=$ neonatal intensive care unit; $\mathrm{HOME}=$ home observation for measurement of the environment.

In the domain of growth, development, and all, the HOF-achieved group was $73.7 \%, 72.4 \%$, and $52.6 \%$, respectively. Of the three growths, the achievement rate for head circumference was the lowest at $81.6 \%$. The achievement rate for the development domain was $72.4 \%$ on the Psychomotor Development Index, which was lower than on the Mental Development Index.

\section{Health status, investment resources, and anthropological values by HOF}

In Table 2, HOF in growth was associated with four variables of health status. Children who achieved HOF in growth weighed more 
Table 2. Health Status, Investment Resources, and Anthropological Values by HOF

$(\mathrm{N}=76)$

\begin{tabular}{|c|c|c|c|c|c|c|c|c|c|}
\hline \multirow{3}{*}{ Factors associated with HOF } & \multicolumn{3}{|c|}{ Growth } & \multicolumn{3}{|c|}{ Development } & \multicolumn{3}{|c|}{ All } \\
\hline & \multicolumn{3}{|c|}{ Mean (SD) or Frequency (\%) } & \multicolumn{3}{|c|}{ Mean (SD) or Frequency (\%) } & \multicolumn{3}{|c|}{ Mean (SD) or Frequency (\%) } \\
\hline & Achieve & Uncertain & $\chi^{2}$ ort $(p)$ & Achieve & Uncertain & $\chi^{2}$ ort $(p)$ & Achieve & Uncertain & $\chi^{2} \operatorname{ort}(p)$ \\
\hline \multicolumn{10}{|l|}{ Health status } \\
\hline Gestational age (week) & $33.8(2.1)$ & $32.8(2.5)$ & $1.65(.103)$ & $33.5(2.2)$ & $33.7(2.2)$ & $-0.29(.775)$ & $33.9(2.0)$ & $33.2(2.5)$ & $1.33(.188)$ \\
\hline Birth weight (gram) & $2207(465)$ & $1838(572)$ & $2.87(.005)$ & $2103(512)$ & $2127(546)$ & $-0.18(.858)$ & $2232(428)$ & $1975(579)$ & $2.18(.033)$ \\
\hline Apgar score at 5 minutes & $7.9(1.14)$ & $7.3(1.63)$ & $1.81(.074)$ & $7.8(1.37)$ & $7.5(1.12)$ & $0.92(.360)$ & $8.0(1.11)$ & $7.4(1.44)$ & $1.96(.054)$ \\
\hline NICU length of stay (day) & $20.1(15.5)$ & $33.6(21.5)$ & $-2.57(.016)$ & $23.5(18.9)$ & $24.2(16.2)$ & $-0.15(.879)$ & $19.1(15.1)$ & $28.8(20.0)$ & $-2.35(.022)$ \\
\hline Twins & $19(33.9)$ & $1(5.0)$ & $6.36(.012)$ & $16(29.1)$ & $4(19.0)$ & $0.79(.374)$ & $15(37.5)$ & $5(13.9)$ & $5.45(.020)$ \\
\hline Cesarean delivery & $40(71.4)$ & $13(65.0)$ & $0.29(.591)$ & $39(70.9)$ & $14(66.7)$ & $0.13(.719)$ & $28(70.0)$ & $25(69.4)$ & $0.00(.958)$ \\
\hline Health problems of child at birth & $17(30.4)$ & $7(35.0)$ & $0.15(.701)$ & $19(34.5)$ & $5(23.8)$ & $0.81(.368)$ & $14(35.0)$ & $10(27.8)$ & $0.46(.499)$ \\
\hline Current health problems of child & $21(37.5)$ & $9(45.0)$ & $0.35(.556)$ & $22(40.0)$ & $8(38.1)$ & $0.23(.879)$ & $15(37.5)$ & $15(41.7)$ & $0.14(.711)$ \\
\hline Maternal age at birth (year) & $31.5(3.9)$ & $32.8(3.9)$ & $-1.28(.205)$ & $31.7(4.23)$ & $32.1(3.07)$ & $-0.41(.687)$ & $31.4(4.21)$ & $32.3(3.60)$ & $-0.97(.336)$ \\
\hline Perinatal health problems of mothers & $38(67.9)$ & $19(95.0)$ & $5.79(.016)$ & $50(90.9)$ & $21(100.0)$ & $2.04(.153)$ & $26(45.6)$ & $14(73.7)$ & $4.50(.034)$ \\
\hline \multicolumn{10}{|l|}{ Investment resources } \\
\hline High school graduated mothers & $26(72.2)$ & $10(27.8)$ & $0.08(.784)$ & $30(83.3)$ & $6(16.7)$ & $4.11(.043)$ & $22(61.1)$ & $14(38.9)$ & $1.97(.160)$ \\
\hline Mothers with employment & $33(70.2)$ & $14(29.8)$ & $0.38(.538)$ & $18(69.2)$ & $8(30.8)$ & $0.79(.779)$ & $14(53.8)$ & $12(46.2)$ & $0.16(.688)$ \\
\hline High school graduated fathers & $26(46.4)$ & $7(35.0)$ & $0.78(.376)$ & $29(52.7)$ & $4(19.0)$ & $7.02(.008)$ & $22(55.0)$ & $11(30.6)$ & $4.61(.032)$ \\
\hline Fathers having a regular job & $41(91.1)$ & $18(94.7)$ & $0.24(.621)$ & $41(93.2)$ & $18(90.0)$ & $0.19(.660)$ & $30(93.8)$ & $29(90.6)$ & $0.22(.999)$ \\
\hline Duration of breast feeding (month) & $7.0(7.2)$ & $8.1(7.7)$ & $-0.53(.597)$ & $6.6(6.1)$ & $9.2(9.7)$ & $-1.44(.154)$ & $6.1(5.85)$ & $8.6(8.5)$ & $-1.50(.139)$ \\
\hline Number in family & $4.3(1.1)$ & $4.1(0.8)$ & $1.09(.281)$ & $4.4(1.1)$ & $3.9(0.7)$ & $2.19(.032)$ & $4.6(1.2)$ & $3.9(0.8)$ & $2.68(.009)$ \\
\hline HOME & $39.1(3.3)$ & $38.1(3.4)$ & $1.11(.273)$ & $38.9(3.3)$ & $38.5(3.5)$ & $0.53(.600)$ & $39.2(3.3)$ & $38.3(3.3)$ & $1.17(.245)$ \\
\hline Grandparental help for child not available & $37(71.2)$ & $15(28.8)$ & $0.54(.461)$ & $43(82.7)$ & $9(17.3)$ & $8.78(.003)$ & $30(57.7)$ & $22(42.3)$ & $1.69(.193)$ \\
\hline Child care resources in the community & $6(10.7)$ & $1(5.0)$ & $0.58(.448)$ & $7(12.7)$ & $0(0.0)$ & $2.94(.086)$ & $6(15.0)$ & $1(2.8)$ & $3.39(.111)$ \\
\hline \multicolumn{10}{|l|}{ Anthropological values } \\
\hline Female child & $25(69.4)$ & $11(30.6)$ & $0.63(.426)$ & $29(80.5)$ & $7(19.5)$ & $2.29(.130)$ & $19(52.8)$ & $17(47.2)$ & $0.00(.981)$ \\
\hline Birth order $\geq 2$ nd & $31(60.8)$ & $20(39.2)$ & $0.05(.829)$ & $34(82.9)$ & $7(17.1)$ & $4.98(.026)$ & $25(61.0)$ & $16(39.0)$ & $3.13(.210)$ \\
\hline Having brothers & $25(44.6)$ & $9(45.0)$ & $0.00(.978)$ & $25(45.5)$ & $9(42.9)$ & $0.04(.839)$ & $18(45.0)$ & $16(44.1)$ & $0.00(.961)$ \\
\hline Having sisters & $27(48.2)$ & $8(40.0)$ & $0.40(.527)$ & $29(52.7)$ & $6(28.6)$ & $3.57(.059)$ & $22(55.0)$ & $13(36.1)$ & $2.72(.099)$ \\
\hline Current maternal age (year) & $34.5(4.0)$ & $36.2(4.1)$ & $-1.59(.115)$ & $34.8(4.3)$ & $35.4(3.4)$ & $-0.60(.549)$ & $34.4(4.1)$ & $35.7(3.9)$ & $-1.43(.158)$ \\
\hline PSI & $84.3(16.4)$ & $79.8(17.7)$ & $1.05(.296)$ & $81.3(16.4)$ & $87.9(16.2)$ & $-1.58(.119)$ & $81.8(15.6)$ & $84.5(17.5)$ & $-0.73(.471)$ \\
\hline MAI & $97.0(7.2)$ & $95.3(7.9)$ & $0.88(.380)$ & $96.3(7.1)$ & $97.3(8.3)$ & $-0.57(.572)$ & $96.9(6.7)$ & $96.1(8.2)$ & $0.46(.646)$ \\
\hline
\end{tabular}

$\mathrm{HOF}=$ health in optimal fitness; $\mathrm{NICU}=$ neonatal intensive care unit; $\mathrm{d}=$ days; $\mathrm{y}=$ years; $\mathrm{m}=$ months; $\mathrm{HOME}=$ home observation for measurement of the environment; $\mathrm{PSI}=$ Parenting Stress Index; MAI = Maternal Attachment Inventory.

$(\mathrm{t}=2.87, p=.005)$ and stayed in the NICU for a shorter period of time $(\mathrm{t}=$ -2.57, $p=.016)$. More children were twins $(\mathrm{t}=6.36, \mathrm{p}=.012)$ and mothers had no perinatal health problems $\left(\chi^{2}=5.79, p=.016\right)$. HOF in development was associated with four variables of investment resources and one variable of anthropological values. More children who achieved HOF in development had parents (mothers: $\chi^{2}=4.11, p=.043$ and fathers: $\chi^{2}=7.02$, $p=.008)$ who graduated high school and had more family members $(\mathrm{t}=2.19, p=.032)$. In addition, more children had no grandparents to help with child care $\left(\chi^{2}=8.78, p=.003\right)$ and were second or later in birth order $\left(\chi^{2}=4.98, p=.026\right)$ in HOF-achieved. HOF in all was associated with four variables of health status and two variables of investment resources. Children who achieved HOF in all weighed more $(\mathrm{t}=2.18, p=.033)$ and stayed in the NICU for a shorter period of time $(\mathrm{t}=-2.35, p=.022)$. In addition, more children were twins $\left(\chi^{2}=5.45, p=.020\right)$ and had fathers who graduated high school $\left(\chi^{2}=4.61, p=.032\right)$ and had more family members $(\mathrm{t}=2.68, p=.009)$. Fewer children had mothers with perinatal health problems $\left(\chi^{2}=4.50, p=.034\right)$.

\section{Logistic regression analysis to predict HOF-Uncertain}

Table 3 presents the results of logistic regression analysis to predict HOF uncertain with factors of health status, investment resources, and anthropological values. In Model 1, no variable was a statistically significant independent contributor for HOF uncertain in growth. However, statistically significant independent contributors were found for HOFuncertain in development and all. The factors predicting HOF uncertain in development included heavier birth weight, longer length of stay in the NICU, fewer family members, fathers who attended college or even had higher education, no grandparents to help with the child, mothers with employment, and older mothers. The factors predicting HOF-uncertain in all included longer length of stay in the NICU, worse score on 
Table 3. Logistic Regression Analysis to Evaluate Determinants of HOF-Uncertain with Selected Factors in the Whole Domains

$(\mathrm{N}=76)$

\begin{tabular}{|c|c|c|c|c|c|c|}
\hline \multirow{2}{*}{ Factors: Adjusted $O R ; 95 \%$ (Cl) } & \multicolumn{2}{|c|}{ Growth } & \multicolumn{2}{|c|}{ Development } & \multicolumn{2}{|c|}{ All } \\
\hline & Model 1 & Model 2 & Model 1 & Model 2 & Model 1 & Model 2 \\
\hline \multicolumn{7}{|l|}{ Health status } \\
\hline Gestational age & $0.8(0.1,8.1)$ & & $3.9(0.1,105.5)$ & & $0.4(0.0,4.4)$ & \\
\hline Birth weight & $0.2(0.0,1.7)$ & $0.3(0.1,1.4)$ & $78.9(1.4,4588.4)$ & $6.4(0.9,46.9)$ & $0.8(0.1,6.6)$ & $0.5(0.1,2.2)$ \\
\hline Twins & $0.2(0.0,3.9)$ & & $77.3(0.6,9871.4)$ & & $2.3(0.2,32.0)$ & \\
\hline NICU length of stay & $2.7(0.2,31.5)$ & $3.4(0.6,19.2)$ & $333.5(7.6,14561.0)$ & $14.3(1.8,113.4)$ & $16.9(1.6,183.4)$ & $7.8(1.5,40.5)$ \\
\hline Perinatal health problems of mothers & $1.1(0.1,21.3)$ & & $22.2(0.4,1222.3)$ & & $1.7(0.2,19.4)$ & \\
\hline \multicolumn{7}{|l|}{ Investment resources } \\
\hline Maternal education & $2.4(0.3,18.6)$ & & $0.3(0.0,2.7)$ & & $0.5(0.1,3.4)$ & \\
\hline Number in family & $1.0(0.2,5.5)$ & $0.6(0.2,2.6)$ & $0.1(0.0,0.1)$ & $0.2(0.1,1.1)$ & $0.3(0.1,2.0)$ & $0.3(0.1,1.4)$ \\
\hline Paternal education & $0.4(0.1,2.6)$ & $0.5(0.1,1.9)$ & $0.1(0.0,0.8)$ & $0.2(0.0,0.9)$ & $0.2(0.0,1.8)$ & $0.3(0.1,1.1)$ \\
\hline Duration of breast feeding & $5.0(0.9,27.2)$ & & $0.4(0.0,4.3)$ & & $5.0(0.9,28.9)$ & \\
\hline HOME & $0.1(0.0,1.2)$ & $0.2(0.0,0.8)$ & $0.2(0.0,1.6)$ & $0.1(0.0,0.8)$ & $0.1(0.0,0.4)$ & $0.1(0.0,0.4)$ \\
\hline Grandparental help for child & $1.0(0.2,6.6)$ & $1.4(0.3,6.5)$ & $0.1(0.0,0.7)$ & $0.1(0.0,0.5)$ & $0.4(0.1,2.1)$ & $0.3(0.1,1.3)$ \\
\hline Mothers with employment & $1.8(0.2,14.4)$ & $3.0(0.7,13.3)$ & $34.5(2.1,580.3)$ & $4.1(0.8,21.6)$ & $17.9(1.5,218.4)$ & $5.7(1.2,27.6)$ \\
\hline \multicolumn{7}{|l|}{ Anthropological values } \\
\hline Female child & $1.6(0.3,7.2)$ & & $0.2(0.0,1.7)$ & & $1.6(0.3,7.5)$ & \\
\hline Birth order & $0.5(0.1,2.7)$ & & $0.1(0.0,1.2)$ & & $0.2(0.1,1.2)$ & \\
\hline Current maternal age & $2.6(0.4,15.6)$ & $3.4(0.9,13.1)$ & $41.9(3.2,543.6)$ & $7.1(1.4,37.0)$ & $24.5(3.2,189.1)$ & $8.8(2.1,37.3)$ \\
\hline PSI & $0.3(0.0,1.8)$ & & $10.8(0.9,131.7)$ & & $3.6(0.6,22.2)$ & \\
\hline MAI & $0.4(0.1,2.3)$ & & $1.2(0.1,11.3)$ & & $1.0(0.2,4.7)$ & \\
\hline$R^{2}, F(p)$ & $.53,6.87(.550)$ & $.34,6.29(.506)$ & $.68,2.12(.977)$ & $.50,2.31(.941)$ & $.64,5.27(.728)$ & $.54,5.50(.703)$ \\
\hline
\end{tabular}

$\mathrm{HOF}=$ health in optimal fitness; $\mathrm{OR}=$ odds ratio; $\mathrm{Cl}=$ confidence interval; $\mathrm{NICU}=$ neonatal intensive care unit; $\mathrm{HOME}=$ home observation for measurement of the environment; $\mathrm{PSI}=$ Parenting Stress Index; $\mathrm{MAI}=$ Maternal Attachment Inventory.

Coding condition for Model 1: gestational age $\geq 33$ weeks; birth weight $\geq 2,100 \mathrm{~g}$; twins; NICU length of stay $\geq 21$ days; perinatal health problems of mothers; high school graduated mothers; mothers with employment; high school graduated fathers; duration of breast feeding $\geq 6$ months; number in family $\geq 5$; HOME $\geq 38$; grandparental help for child not available; female child; birth order $\geq 2$ nd; current maternal age $\geq 35$ years; $P S I \geq 97 ; M A I ~ \geq 96$.

Coding condition for Model 2: birth weight $\geq 2,100$ g; NICU length of stay $\geq 21$ days; number in family $\geq 5$; high school graduated fathers; HOME $\geq 38$; grandparental help for child not available; mothers with employment; current maternal age $\geq 35$ years.

the HOME, mothers with employment, and older mothers.

In Model 2, worse score on the HOME was the only statistically significant contributor to HOF-uncertain in growth. The factors predicting HOF-uncertain in development included longer length of stay in the NICU, having fathers who attended college or even had higher education, worse score on the HOME, no grandparents to help with the child, and having older mothers. The factors predicting HOF-uncertain in all included longer length of stay in the NICU, worse score on the HOME, mothers with employment, and older mothers.

\section{Discussion}

In this case-control study we examined factors affecting the growth and development of children with PTB based on Ahn's HOF theory[7]. We selected health status, investment resources, and anthropological values for children with PTB. Through data analysis, we deduced the following four points. First, children with PTB had a high risk of being uncertain in HOF. In this study, almost half of the children did not achieve HOF in all. This result supports the findings of several studies that have pointed out the risk of delayed growth and development in children with PTB 2 24] . In particular, one fifth of children with PTB did not achieve HOF in growth, and of weight, height, and head circumference, uncertainty of head circumference growth was highest at $18.4 \%$. Head circumference is known to be closely related to neurologic development[22] and tends to be less commonly measured than weight and height at a regular growth checkup in Korea.

We also identified high uncertainty rates (27.6\%) in the children's development. Voigt et al[2] documented that very young children with PTB had lower scores $(93.2 \pm 15.7)$ on the Mental Development Index than children born at full-term $(106.3 \pm 8.9)$. In our study, average scores for the two indices of children with PTB were within normal ranges (94.5 and 91.8, respectively), however, they were still slightly lower than those reported by Cho and Park[15]. Cho and Park[15] reported that the average scores of Korean children aged 24 to 42 months old who were born as healthy full-term infants were 99.1-102.4 and 108-111.1, respectively. 
Second, we found that children's health status early in life continuously affects their HOF, even 24 to 42 months after birth. The length of NICU stay was a statistically significant independent contributor of HOF-uncertain in the domain of development (adjusted OR $=14.3,95 \%$ CI $[1.8,113.4]$ ) and all (adjusted OR=7.8, 95\% CI[1.5, 40.5]) even after controlling for birth weight and related factors in HOF theory. The NICU environment is necessary not only for medical treatment but also for the active growth and development that should have occurred in the womb. However, children with PTB in the NICU face two challenges: excessive exposure to noxious stimulation (e.g., pain, continuous noise and lights, and frequent touching by medical staff) and the lack of developmental stimulation that they would otherwise have received in their mother's womb[22]. These factors raise the risk of HOF-uncertain. Thus, the length of NICU stays should be minimized to avoid unnecessary burden, while striving to provide a development-friendly environment for high-risk newborns such as a premature infant.

Third, we confirmed the importance of investment resources in HOF for children with a history PTB. HOME scores reflect the quality and quantity of the material and psychological environment in a child's home[16]. Oliveira et al.[5], who evaluated the HOME scores of children with PTB, indicated that low scores reflect negative environmental factors that could impede their development. They reported that HOME scores in children with very low birth weight $(33.8 \pm 7.8)$ were significantly lower than in children with normal birth weight (39.6 \pm 8.8$)$, and higher scores had a significant, positive correlation with better cognitive $(\mathrm{r}=0.35, p<.05)$ and motor development $(\mathrm{r}=0.35, p<.05)$ in children aged 5 and 6 . Our study findings emphasize the critical value of stimulation and support at home in modulating the growth and development of children with PTB and shows HOME as the only independent contributor of HOF in growth, development, and all after controlling for all selected factors.

We also found that children who had an at-home mother, no grandparental help for child care, and more family members were more likely to achieve HOF in the domain of just development or development and all. In Korea, there is no federal financial support for day care, which can be very expensive and unaffordable for young parents. In addition, women often find it difficult to keep their job after returning from maternity leave. Inevitably, this forces many mothers to resign. The Korea Institute for Health and Social Affairs[25] has reported that the employment rate of women after their first child decreased from $31.0 \%$ to $25.4 \%$. The intensive care demanded for children with PTB may also explain why women choose to stay at home rather than pursue their career. This may explain the positive effect of an at-home mother with no grandparental help on the HOF of Korean children with PTB. A previous study proposed that maternal employment would have a negative effect on the weight gain of preterm Korean infants at 6 months of corrected age[4]. Our results seem to bear this out. Also, more family members could indicate the presence of siblings, and children who are not firstborn have more opportunities to interact with older siblings and receive care from experienced parents[26]. Although birth order was not an independentrelated factor for HOF in our study, having more family members (i.e., siblings or others) may still support the significance of human interaction on HOF in children with PTB.

Finally, we found that maternal age was the only independent contributor to HOF among anthropological values. Previous researchers have reported that very young or advanced maternal age is associated with poor growth in children[27], and very young maternal age is also associated with poor child development[28]. However, the association between advanced maternal age and child development has been rarely studied. In our study, mothers aged 35 and older were at great risk of HOF-uncertain in the domain of development and all, which suggests the potential disadvantage of development in children born to mothers of advanced age. However, this finding is inconsistent with a study reporting the positive effect of increasing maternal age on language development in children[29]. In the study by Sutcliffe et al.[29], mothers over 35 years of age tended to be better educated and have higher family income, which could provide a high quality environment for child development. However, other authors suggested that children born to older women may experience negative development because mothers over 35 showed lower scores in parenting attitude than those under 35[30]. Thus, further studies are necessary to explore the effect of advanced maternal age on various areas of child development using a wide range of ages. Our study has some limitations. The convenience sample was recruited from only one university hospital. Thus, the generalizability of this study's results is limited. In this study, interpretation of the associations among variables is limited due to the cross sectional study design and potential selection bias; the response rate was low (58.4\%) and the refusal rate $(43.7 \%)$ relatively high. We recommend a qualitative approach to improve understanding on the phenomenon related to HOF theory. Finally, we may not have accounted for all potential confounding factors such as heterogeneity of prematurity, characteristics of primary caregiver, and types of home environments. 


\section{Conclusion}

We conducted this case-control study to explore the HOF status and the influencing factors of young children born prematurely in Korea. Findings indicate that children with PTB show high rates of HOF-uncertain for growth, development, and all. Considering that the children did not have acute brain diseases with AGA over 28 weeks at birth, the high risk of HOF-uncertain may suggest that even relatively healthy children with PTB may experience delayed growth and development. Furthermore, we found that socioeconomic characteristics of the family are significantly associated factors in children's growth and development. Clinicians should be aware of the importance of consistent assessment of growth and development for children with a PTB history and noted risk factors. For example, head circumference should be measured and evaluated at regular health examinations for all children with a PTB history for at least the first 3-4 years of life. Further, for the optimal growth and development of preterm children, NICUs must become more developmentally friendly environments. Children at risk should be referred to programs that can recognize sociocultural risk factors, manage clinical conditions such as prolonged stays in an NICU, and provide developmental care based on individual needs.

\section{Conflict of Interest}

No potential conflict of interest relevant to this article was reported.

\section{Acknowledgements}

This manuscript is based on the first author's doctoral dissertation from Inha University. This research was supported by Basic Science Research Program through the National Research Foundation of Korea (NRF) funded by the Ministry of Science, ICT \& Future Planning (grant number: NRF-2014R1A1A1002091).

\section{References}

1. Korean Statistical Information Service. Birth according to gestational age[Internet]. Daejeon: Statistics Korea; 2015[cited 2016 Jun 10]. Available from: http://kosis.kr/statHtml/statHtml.do?orgId=101\&tblid =DT_1B81A15\&conn_path=I2.

2. Voigt B, Pietz J, Pauen S, Kliegel M, Reuner G. Cognitive development in very vs. moderately to late preterm and full-term children: can effortful control account for group differences in toddlerhood? Early Human Development. 2012;88(5):307-313. http://dx.doi.org/10.1016/ j.earlhumdev.2011.09.001

3. Euser AM, de Wit CC, Finken MJ, Rijken M, Wit JM. Growth of preterm born children. Hormone Research. 2008;70(6):319-328. http:// dx.doi.org/10.1159/000161862

4. Ahn Y, Sohn M, Lee S. Growth of Korean preterm infants in a familycentered tradition during early infancy: the influence of health risks, maternal employment, and the sex of infants. Japan Journal of Nursing Science. 2014;11(4):281-289. http://dx.doi.org/10.1111/jjns.12033

5. Oliveira GE, Magalhães LC, Salmela LF. Relationship between very low birth weight, environmental factors, and motor and cognitive development of children of 5 and 6 years old. Revista Brasileira de Fisioterapia. 2011;15(2):138-145. http://dx.doi.org/10.1590/S141335552011000200009

6. Dunbar R, Barrett L, Lycett J. Evolutionary psychology. Oxford (UK): Oneworld Publications; 2005. p. 240.

7. Ahn YM. Theory for health for optimal fitness in health care for highrisk children. Journal of Korean Academy of Child Health Nursing. 2009;15(1):42-52. http://dx.doi.org/10.4094/jkachn.2009.15.1.42

8. Bowlby J. Attachment and loss: Vol. 1. Attachment. New York (NY): Basic Books; 1969. p. 428.

9. Korean Statistical Information Service. 2014 total fertility rate[Internet]. Daejeon: Statistics Korea; 2015[cited 2016 Jun 5]. Available from: http://kosis.kr/statHtml/statHtml.do?orgId=101\&tblId=DT_1B81A21 \&conn_path=I2.

10. Ahn Y, Sohn M, Yoo E. Breast functions perceived by Korean mothers: infant nutrition and female sexuality. Western Journal of Nursing Research. 2010;32(3):363-378. http://dx.doi.org/10.1177/0193945909349252

11. Korean Women's Development Institute The 16th reports for the Women's Week: jobs of Korean women comparing with OECD data[Internet]. Seoul: Author; 2011[cited 2016 Jun 10]. Available from: http://www.kwdi.re.kr/noticeView.kw?sgrp=S01\&siteCmsCd=CM000 1\&topCmsCd=CM0029\&cmsCd=CM0038\&pnum $=2 \& \mathrm{cnum}=0 \& \mathrm{src}$ $=$ TITLE\&srcTemp $=\% \mathrm{EC} \% \mathrm{~B} 7 \% \mathrm{~A} 8 \% \mathrm{EC} \% 97 \% 85 \& \mathrm{x}=0 \& \mathrm{y}=0 \& \mathrm{ntNo}=41$ $7 \& d v s n=\&$ currtPg=1

12. Bayley N. Bayley Scales of Infant Development. 2nd ed. San Antonio (TX): Psychological Corporation; 1993.

13. Moon JS, Lee SY, Nam CM, Choi JM, Choe BK, Seo JW, et al. 2007 Korean national growth charts: review of developmental process and 
outlook. Korean Journal of Pediatrics. 2008;51(1):1-25. http://dx.doi. org/10.3345/kjp.2008.51.1.1

14. Mudahemuka JC, Ballot DE. Birth weight recovery among very low birth weight infants surviving to discharge from Charlotte Maxeke Johannesburg Academic Hospital. South African Journal of Child Health. 2014;8(4):149-153. http://dx.doi.org/:10.7196/SAJCH.709

15. Cho BH, Park HW. The standardization study (1) of Korean Bayley Scales of Infant Development (K-BSID-II): analyses of Korean infants performance of K-BSID-II in terms of demographical variables. The Korean Journal of Developmental Psychology. 2004;17(1):191-206.

16. Caldwell BM, Bradley RH. Home observation for measurement of the environment. Little Rock (AR): Center for Child Development and Education, University of Arkansas; 1984.

17. Lee Y. A preliminary study for the standardization of the HOME for families of infants and toddlers. Yonsei Theses. 1985;21(3):379-397.

18. Müller ME. A questionnaire to measure mother-to-infant attachment. Journal of Nursing Measurement. 1994;2(2):129-141.

19. Han KE. The relationship of maternal self-esteem and maternal sensitivity with mother-to-infant attachment[master's thesis]. Seoul: Hanyang University; 2001.

20. Abidin RR. Parenting stress index. 3rd ed. Odessa (FL): Psychological Assessment Resources, Inc; 1995.

21. Lee KS, Chung KM, Park JA, Kim HJ. Reliability and validity study for the Korean version of parenting stress index short form (K-PSI-SF). The Korean Journal of Woman Psychology. 2008;13(3):363-377. http:// dx.doi.org/10.18205/kpa.2008.13.3.007

22. Hockenberry MJ, Wilson D. Wong's nursing care of infants and children. 10th ed. St. Louis: Mosby; 2015. p.353-440.
23. Yeşinel S, Aldemir EY, Kavuncuoğlu S, Yeşinel S, Yıldız H. Evaluation of growth in very low birth weight preterm babies. Turkish Archives of Pediatrics. 2014;49(4):289-298. http://dx.doi.org/10.5152/tpa.2014.1989

24. Ma TH, Kim KA, Ko SY, Lee YK, Shin SM. Catch-up growth and development of very low birth weight infants. Korean Journal of Pediatrics. 2006;49(1):29-33. http://dx.doi.org/10.3345/kjp.2006.49.1.29

25. Korea Institute for Health and Social Affairs. The 2012 national survey on fertility, family health \& welfare in Korea[Internet]. Seoul: Author; 2012 [cited 2016 Jun 20]. Available from: https://www.kihasa.re.kr/ $\mathrm{html} /$ jsp/publication/research/view.jsp?bid=12\&ano=1465\&key=title\& query.

26. McHale SM, Updegraff KA, Whiteman SD. Sibling relationships and influences in childhood and adolescence. Journal of Marriage and Family. 2012;74(5):913-930. http://dx.doi.org/ 10.1111/j.1741-3737.2012.01011.x 27. Myrskylä M, Fenelon A. Maternal age and offspring adult health: evidence from the health and retirement study. Demography. 2012;49(4): 1231-1257. http://dx.doi.org/ 10.1007/s13524-012-0132-x

28. Chittleborough CR, Lawlor DA, Lynch JW. Young maternal age and poor child development: predictive validity from a birth cohort. Pediatrics. 2011;127(6):1436-1444. http://dx.doi.org/10.1542/peds.20103222

29. Sutcliffe AG, Barnes J, Belsky J, Gardiner J, Melhuish E. The health and development of children born to older mothers in the United Kingdom: observational study using longitudinal cohort data. British Medical Journal. 2012;345:5116. http://dx.doi.org/10.1136/bmj.e5116

30. Kim SJ, Kim KS, Kim YH. Preschool children mother's child rearing attitude using Korean parent as a teacher test. Korean Parent-Child Health Journal. 2007;10(1):3-12. 